\title{
The population genomics of adaptive loss of function
}

\author{
J. Grey Monroe ${ }^{1,2} \cdot$ John K. McKay $^{3} \cdot$ Detlef Weigel $^{1} \cdot$ Pádraic J. Flood $\mathbb{1}^{4,5}$
}

Received: 24 September 2020 / Revised: 28 December 2020 / Accepted: 1 January 2021 / Published online: 11 February 2021

(c) The Author(s) 2021. This article is published with open access

\begin{abstract}
Discoveries of adaptive gene knockouts and widespread losses of complete genes have in recent years led to a major rethink of the early view that loss-of-function alleles are almost always deleterious. Today, surveys of population genomic diversity are revealing extensive loss-of-function and gene content variation, yet the adaptive significance of much of this variation remains unknown. Here we examine the evolutionary dynamics of adaptive loss of function through the lens of population genomics and consider the challenges and opportunities of studying adaptive loss-of-function alleles using population genetics models. We discuss how the theoretically expected existence of allelic heterogeneity, defined as multiple functionally analogous mutations at the same locus, has proven consistent with empirical evidence and why this impedes both the detection of selection and causal relationships with phenotypes. We then review technical progress towards new functionally explicit population genomic tools and genotype-phenotype methods to overcome these limitations. More broadly, we discuss how the challenges of studying adaptive loss of function highlight the value of classifying genomic variation in a way consistent with the functional concept of an allele from classical population genetics.
\end{abstract}

\section{The historical context}

Views on loss-of-function mutations - those abolishing a gene's biomolecular activity-have changed considerably over the last half century. Early theories of molecular evolution that emerged during the 1960's and 1970's saw little potential for loss-of-function mutations to contribute to adaptation (Maynard Smith 1970). Except in the case of inactivated gene duplicates, nonfunctional alleles were often assumed to be lethal, with adaptation being generally

Associate editor: Frank Hailer

J. Grey Monroe

gmonroe@ucdavis.edu

1 Department of Molecular Biology, Max Planck Institute for Developmental Biology, 72076 Tübingen, Germany

2 Department of Plant Sciences, University of California Davis, Davis, CA 95616, USA

3 College of Agriculture, Colorado State University, Fort Collins, CO 80523, USA

4 Department of Plant Developmental Biology, Max Planck Institute for Plant Breeding Research, 50829 Cologne, Germany

5 Department of Plant Breeding, Wageningen University, Wageningen, The Netherlands regarded as a process explained only by the fixation of single, mutationally rare alleles that improved or altered a gene's function (Orr 2005). Only relatively recently, through discoveries enabled by the availability of molecular sequence data, were alternative views of adaptive loss-of-function alleles formalized, most notably with the "less is more" ideas proposed by Olson (1999). Classical paradigms of molecular evolution had by that time been challenged, for example, by evidence that natural loss-of-function variants of CCR5 lead to reduced HIV susceptibility in humans (Libert et al. 1998). Discoveries during the subsequent two decades have continued to support the idea that loss of function contributes to adaptation (Murray 2020), with cases of adaptive or beneficial loss of function being discovered across diverse organisms, genes, traits, and environments (Fig. 1).

Today, reductive genome evolution is viewed as a powerful force of adaptation (Wolf and Koonin 2013) and gene loss is considered an important source of adaptive genetic variation (Albalat and Cañestro 2016; Murray 2020). The flood of -omics data generated in recent years is beginning to reveal the extent of loss of function and gene content variation segregating within species. Pan-genome and pan-transcriptome analyses have found that gene absence variation is pervasive in both prokaryotic and eukaryotic species (Jin et al. 2016; McInerney et al. 2017; Gerdol et al. 2020). And surveys of functional genomic diversity in organisms from Arabidopsis thaliana (Monroe et al. 2018; Xu et al. 2019) to humans 

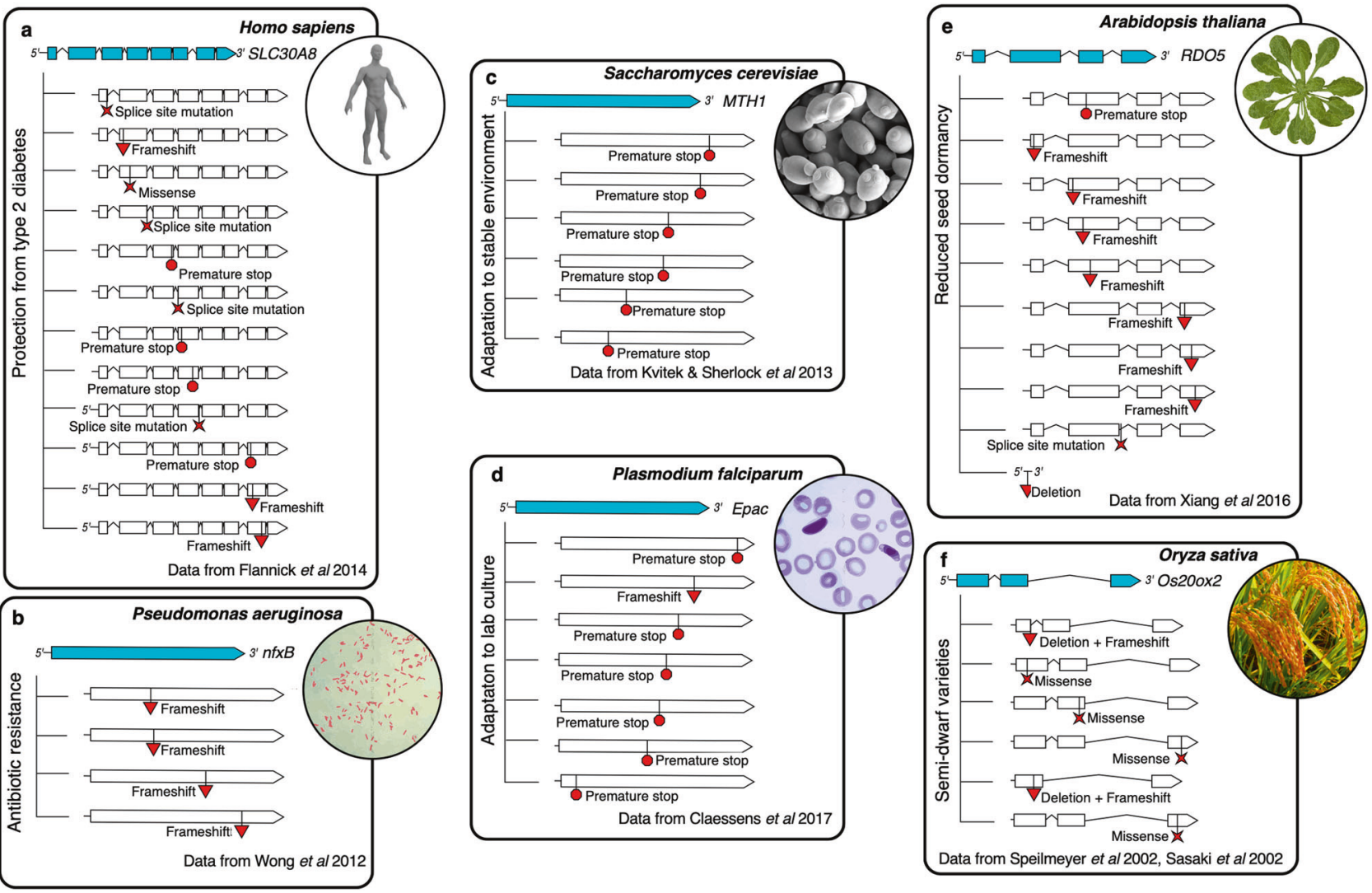

Fig. 1 Examples of genes from different species with adaptive or beneficial loss-of-function alleles. In each example, multiple independent variants can be combined to constitute the population scale loss-of-function allele state. a Loss of function in SLC30A8 is associated with reduced risk of type 2 diabetes in humans (Flannick et al. 2014; Dwivedi et al. 2019). b Experimental evolution in Pseudomonas aeruginosa resulted repeatedly in loss-of-function mutations in $n f x B$, conferring antibiotic resistance (Wong et al. 2012). c Experimental evolution in yeast led to consistent disruption of specific signaling pathway genes including MTH1 during adaptation to stable

(MacArthur et al. 2012; Karczewski et al. 2020) have revealed extensive genetic variation causing predicted loss of function. Yet, the adaptive importance of such variation remains largely unknown.

While the existence of adaptive loss of function is no longer seriously disputed, the assumed maladaptive nature of loss of function from early theories can persist in the language of population genetics such as in the continued use of deleterious as a synonym for loss-of-function (Moyers et al. 2018). Perhaps less visible but more consequential, historical assumptions about loss of function remain implicit in some analyses of DNA sequence variation as many classic tests for evidence of selection or causal relationships with phenotypes are built upon expectations of adaptation only involving hard sweeps of single mutationally rare alleles (Pennings and Hermisson 2006a, b). Contemporary disagreements in population genetics can also reflect differences in views on the functional molecular environments (Kvitek and Sherlock 2013). d Populations of Plasmodium falciparum repeatedly evolved loss-of-function alleles in Epac during adaptation to lab culture environments (Claessens et al. 2017). e Natural RDO5 loss-of-function variants in Arabidopsis thaliana occurred at high frequency in northwest Europe and caused reduced seed dormancy, a trait under strong locally adaptive selection (Xiang et al. 2016). f Adaptation to agricultural intensification led to selection for semi-dwarf rice, which is caused by loss-of-function variants in GA20ox2 (Spielmeyer et al. 2002; Sasaki et al. 2002).

basis of adaptation. This can be seen for instance in alternative perspectives on the relative importance of soft versus hard selective sweeps, a debate which is inherently connected to the propensity for adaptation to involve recurrent loss-of-function mutations (Messer and Petrov 2013; Jensen 2014).

The aim of this article is to examine theoretical and empirical advances describing the population evolutionary dynamics of beneficial loss-of-function alleles, which remain on one hand a low-hanging fruit when it comes to functionally classifying molecular diversity but on the other, a particularly challenging class of molecular variants to study using common population genetics models. We hope this review will facilitate new considerations of the population genomic diversity now being revealed with the widespread generation of whole genome sequence data (Table 1, Fig. 2). We also hope to shed light on some practical challenges confronting population geneticists 
Table 1 Recent whole genome re-sequencing projects with functional annotations of variants. Numbers of premature stop, synonymous, and nonsynonymous single nucleotide polymorphisms indicate number of variants segregating among the genotypes sequenced (Fig. 2 ). Sample Size $=$ number of genotypes sequenced.

\begin{tabular}{|c|c|c|c|c|c|}
\hline Species & Sample size & Premature stops & Synonymous & Non-synonymous & Citation \\
\hline Ananas comosus & 89 & 7,084 & 689,019 & 589,484 & (Chen et al. 2019) \\
\hline Arabidopsis thaliana & 1,135 & 27,813 & 803,665 & $1,135,115$ & (1001 Genomes Consortium 2016) \\
\hline Bos indicus & 20 & 1,132 & 255,296 & 155,251 & (Iqbal et al. 2019) \\
\hline Bos taurus & 15 & 3,837 & $1,155,244$ & 524,103 & (Zhang et al. 2019) \\
\hline Branchiostoma belcheri & 20 & 11,487 & $2,818,189$ & $1,467,863$ & (Bi et al. 2020) \\
\hline Brassica napus & 991 & 1,413 & 120,926 & 79,018 & (Wu et al. 2019) \\
\hline Caenorhabditis elegans & 330 & 5,084 & 271,950 & 261,538 & (Cook et al. 2017) \\
\hline Cairina moschata & 15 & 285 & 36,517 & 19,817 & (Gu et al. 2020) \\
\hline Canis lupus & 722 & 11,273 & 540,063 & 332,559 & (Plassais et al. 2019) \\
\hline Capsella grandiflora & 15 & 5,209 & 644,326 & 478,238 & (Koenig et al. 2019) \\
\hline Capsella orientalis & 16 & 269 & 11,250 & 13,281 & (Koenig et al. 2019) \\
\hline Capsella rubella & 50 & 2,508 & 194,078 & 171,071 & (Koenig et al. 2019) \\
\hline Cicer arietinum & 16 & 352 & 50,290 & 38,078 & (Thudi et al. 2016) \\
\hline Cucumis melo & 1,175 & 7,030 & 102,687 & 94,426 & (Zhao et al. 2019) \\
\hline Cucurbita pepo & 7 & 864 & 156,828 & 111,687 & (Xanthopoulou et al. 2019) \\
\hline Drosophila melanogaster & 205 & 1,532 & 351,255 & 182,520 & (Huang et al. 2014) \\
\hline Ebola virus & 140 & 3 & 555 & 403 & (Ladner et al. 2015) \\
\hline Echinochloa crus-galli & 328 & 9,264 & 184,746 & 319,816 & (Ye et al. 2019) \\
\hline Felis catus & 54 & 838 & 128,844 & 77,662 & (Buckley et al. 2020) \\
\hline Fraxinus excelsior & 37 & 2,997 & 251,249 & 259,946 & (Sollars et al. 2017) \\
\hline Glycine $\max$ & 1,007 & 2,826 & 122,469 & 182,479 & (Torkamaneh et al. 2019) \\
\hline Gossypium spp. & 243 & 6,851 & 101,059 & 128,512 & (Du et al. 2018) \\
\hline Hippotragus niger & 7 & 201 & 11,350 & 11,386 & (Koepfli et al. 2019) \\
\hline Homo sapiens & 141,465 & 133,019 & $2,173,110$ & $4,548,307$ & (Karczewski et al. 2020) \\
\hline Macaca mulatta & 133 & 2,642 & 148,278 & 126,445 & (Xue et al. 2016) \\
\hline Manihot esculenta & 203 & 4,399 & 265,094 & 299,197 & (Ramu et al. 2017) \\
\hline Mycoplasma pneumoniae & 15 & 88 & 4,382 & 6,891 & (Xiao et al. 2015) \\
\hline Oryza sativa & 3,024 & 198,609 & $2,952,705$ & $3,599,083$ & Wang et al. 2018) \\
\hline Parastagonospora nodorum & 197 & 2,815 & 226,803 & 160,159 & (Richards et al. 2019) \\
\hline Phaseolus vulgaris & 683 & 1,352 & 112,173 & 97,536 & (Wu et al. 2020) \\
\hline Populus trichocarpa & 1,014 & 8,365 & 231,894 & 333,036 & (Piot et al. 2019) \\
\hline Protobothrops mисrosquamatus & 22 & 883 & 53,023 & 56,553 & (Aird et al. 2017) \\
\hline Puccinia hordei & 5 & 2,629 & 46,763 & 67,526 & (Chen et al. 2019) \\
\hline Rattus norvegicus & 40 & 285 & 42,182 & 26,239 & (Hermsen et al. 2015) \\
\hline$S A R S-n C o V-2$ & 8,053 & 90 & 2,678 & 4,731 & (Rayko and Komissarov 2020) \\
\hline Saccharomyces cerevisiae & 1,011 & 7,207 & 517,729 & 549,300 & (Peter et al. 2018) \\
\hline Solanum melongena & 7 & 438 & 6,645 & 12,828 & (Gramazio et al. 2019) \\
\hline Solanum tuberosum & 201 & 4,962 & 541,208 & 515,492 & (Li et al. 2018) \\
\hline Sorghum bicolor & 44 & 3,114 & 112,255 & 112,108 & (Mace et al. 2013) \\
\hline Trypanosoma evansi & 15 & 1,685 & 30,714 & 53,002 & (Lazaro et al. 2020) \\
\hline
\end{tabular}

(Figs. 3 and 4) and the intriguing dynamics of loss-offunction alleles through the lens of classic models (Fig. 5). We further discuss advances in sequencing technologies and annotation approaches that are facilitating new ways to discover cases of beneficial loss-of-function and more broadly, syntheses between modern genomics and the functional concept of alleles from classic population genetics (Fig. 6). 


\section{What are loss-of-function alleles?}

Classifying biological diversity into discrete categories has always been difficult. Descriptions of even the most fundamental biological units such as cell types, populations, and species can be challenging. Yet these classifications provide units of study that help make sense of biological and evolutionary phenomena. This is also true for alleles.

The existence of a category of alleles distinguished by a derived loss of biochemical function has been described by various names: "amorphic" (Muller 1932), "loss-of-function" (Jones 1972), "nonfunctional" (Nei and Roychoudhury 1973), "knockout" (Kulkarni et al. 1999),"null"

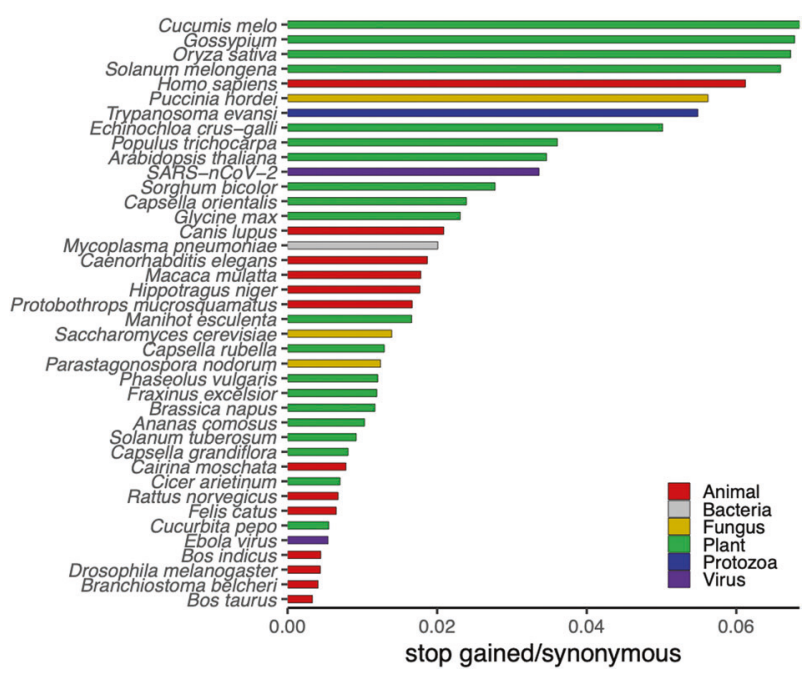

Fig. 2 Rates of putative loss-of-function variants (stop gained) relative to synonymous single nucleotide polymorphisms reported in recent whole genome re-sequencing projects (Table 1). Species exhibit considerable differences in the ratio of stop gained to synonymous single nucleotide polymorphisms, with a 20 -fold difference between the greatest (Cucumis melo) and fewest (Bos taurus) observations. The causes for these differences between species and, more generally, the (mal)adaptive nature of this extensive loss-of-function variation remain largely unknown.
(Engel et al. 1973), "pseudogene" (Jacq et al. 1977), or simply "gene loss" (Zimmer et al. 1980). Total gene loss is the most obvious case of loss of function. Comparisons of gene content between distantly related species have revealed considerable evidence for adaptation via complete deletion of genes or even entire sets of functionally related genes (Wang et al. 2006; Blomme et al. 2006; Will et al. 2010; McLean et al. 2011; Griesmann et al. 2018; van Velzen et al. 2018; Sharma et al. 2018; Huelsmann et al. 2019; McGowen et al. 2020; Baggs et al. 2020). Pangenome analyses have revealed extensive gene content variation segregating within species. For example, the average Brachypodium distachyon genotype is missing almost half of the genes observed in the species pangenome (Gordon et al. 2017). Yet total gene loss is not the only means by which loss of function can occur. In their review of evolution by gene loss, Albalat and Cañestro (2016) point out that single mutations and many mutation types such as premature stop codons, frameshifts, splice site disruptions, and elimination of regulatory regions required for gene expression can have effects that are functionally indistinguishable from complete gene loss. Here we will discuss how the phenomenon of allelic heterogeneity - that numerous types of mutations can produce the same functionally analogous allele-is important for understanding the evolutionary dynamics and implications of adaptation by loss of function.

First principles and empirical evidence indicate that many types of mutations can have effects that are equivalent to total gene loss, and for the purposes of this review, we employ this definition of complete gene losses being functionally equivalent to other loss-of-function mutations such as premature stop codons. However, there is the practical difficulty that these different types of mutations vary in how easily they can be detected and correctly annotated as lossof-function alleles (Fig. 3). Insertions and deletions that interrupt the reading frame of a protein coding region (frameshift mutations), for example, might be readily classified as loss-of-function alleles because the downstream

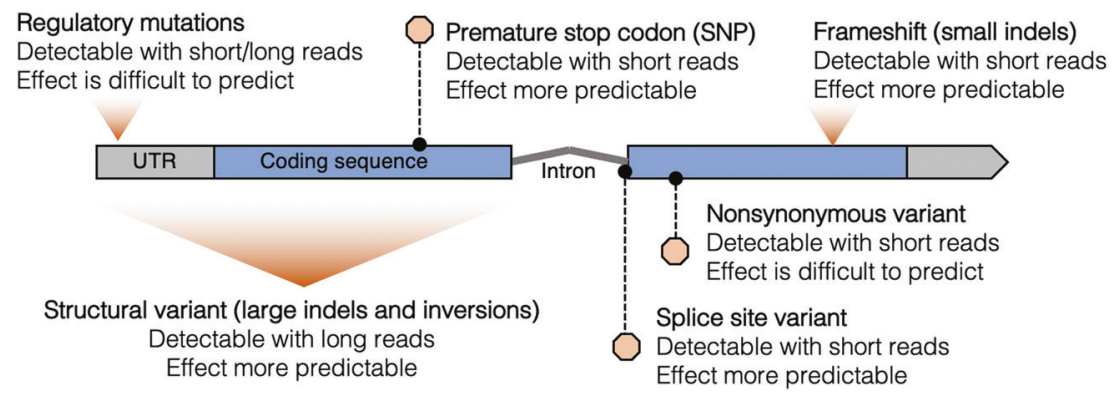

Fig. 3 Examples of loss-of-function (LoF) variants. Shown are those types caused by different kinds of mutations (SNP single nucleotide polymorphism, indel insertions and deletions), which vary in the kind of data needed to detect them (short/long read sequencing) and the predictability of their effect on gene function. 


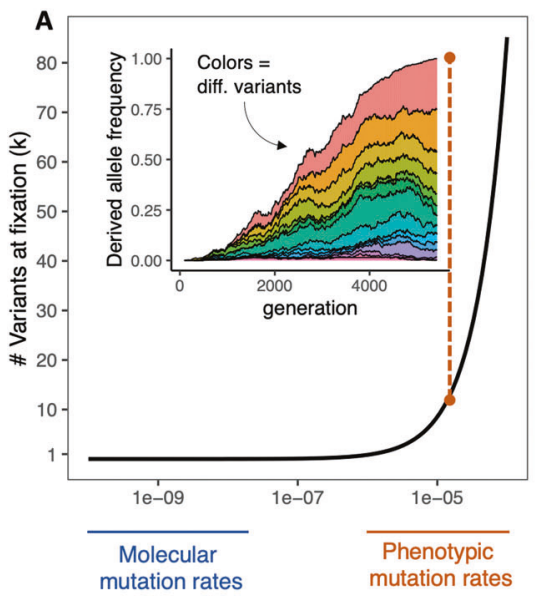

Mutation rate $(\mathrm{u})$

Fig. 4 Theoretical predictions and empirical observations of allelic heterogeneity. a Predicted values of the number of independent variants of the same allele observed at fixation $(k)$ as a function of mutation rates $(u)$. Equation based on Haldane (1927) and Kimura (1962) and taken from Wilson et al. (2014). Predictions are based on an effective population size $\left(N_{e}\right)$ of 50,000 and selection coefficient (s) of 0.01 . Highlighted are frequently observed ranges of empirical estimates of mutation rates from classic population genetics (Muller 1928; Haldane 1933; Rhoades 1941; Stadler 1946, 1948) and sequence-based mutation rates from modern molecular genomics (Lynch et al. 2016). Inset figure illustrates the hypothetical dynamics of multiple independent alleles (each a different color) with positive

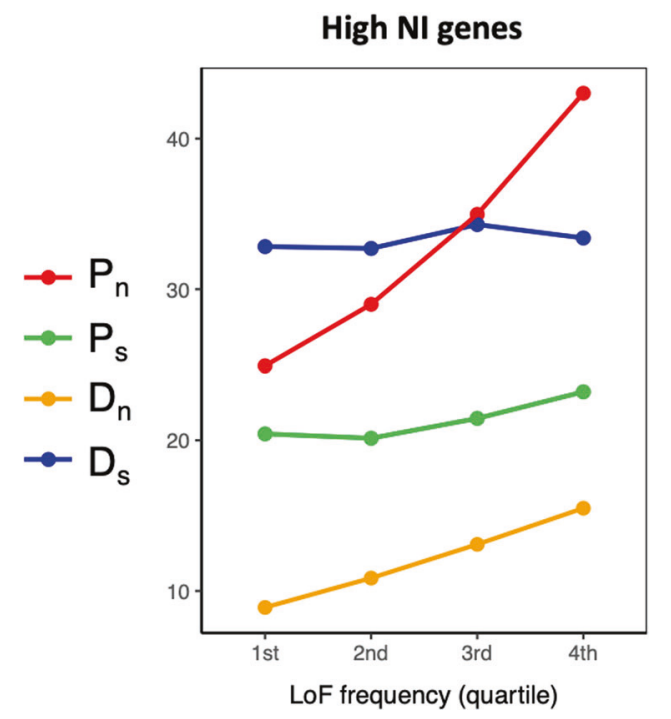

Fig. 5 Among genes with high Neutrality Index (NI), those with a high frequency of loss-of-function alleles are enriched for nonsynonymous polymorphism $\left(\boldsymbol{P}_{\boldsymbol{n}}\right)$. Shown here are mean components of $N I$ in A. thaliana genes with high (top 20\%) NI values in relation to loss-of-function (LoF) allele frequencies (binned by quartiles). Lossof-function calls based on approach from (Monroe et al. 2018; Baggs et al. 2020) and data from (Monroe et al. 2020). $P_{n}=$ non-synonymous polymorphism, $P_{s}=$ synonymous polymorphism, $D_{n}=$ non-synonymous divergence, $D_{s}=$ synonymous divergence (using $A$. lyrata as an outgroup).

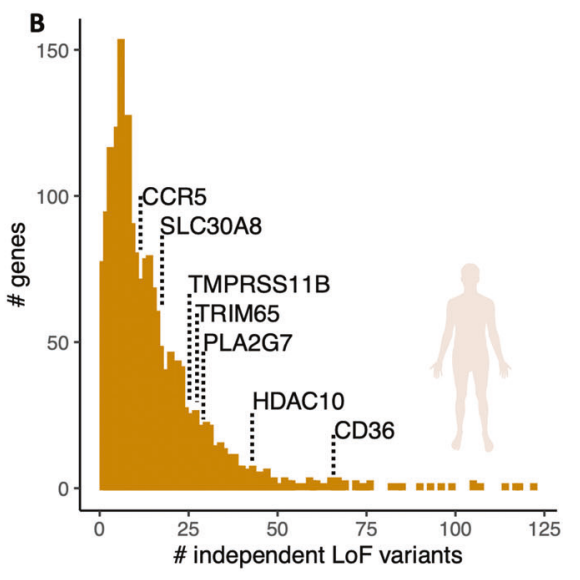

selection. Collectively the variants increase in frequency, ultimately leading to fixation of adaptive variants (elimination of deleterious ancestral allele), but individually each variant remains at low frequency. b Detected levels of allelic heterogeneity in genes enriched for loss of function in humans (obs > exp) reported by (Karczewski et al. 2020). Highlighted are cases of previously studied genes with evidence of beneficial effects or positive selection CCR5 (Libert et al. 1998), SLC30A8 (Flannick et al. 2014; Dwivedi et al. 2019), TMPRSS11B (Updegraff et al. 2018), TRIM65 (Wang et al. 2016; Wei et al. 2018), PLA2G7 (Song et al. 2012), HDAC10 (Dahiya et al. 2020), CD36 (Fry et al. 2009; Love-Gregory et al. 2011).

amino acid sequence will be severely disrupted. Yet a frameshift mutation at the extreme $3^{\prime}$ end of a coding region affecting only a few amino acids might be functionally distinct from a frameshift mutation at the extreme $5^{\prime}$ end disrupting the entire coding sequence. One simple heuristic to address this ambiguity is a threshold, measured by the portion of the gene affected by functionally disruptive mutations, at which an allele is classified as loss-offunction. This approach can be used to classify premature stop codons, frameshift, splice site disruptions, start loss, and inframe insertions and deletions. In humans (MacArthur et al. 2012; Karczewski et al. 2020) and Arabidopsis thaliana (Monroe et al. 2018; Baggs et al. 2020), loss-offunction mutations affecting only a small fraction (e.g., $<10 \%$ ) of total coding sequence in a gene were ignored when classifying loss-of-function variants. Such cutoffs are supported by the observation that even in genes not thought to be experiencing adaptive loss of function, there is an enrichment for otherwise predicted loss-of-function mutations that affect only small fractions of coding regions (MacArthur et al. 2012; Flowers et al. 2009), suggesting reduced functional impact of such variants.

Other single mutations causing loss of function may be even more difficult to predict. Mutations changing functionally critical amino acids can disable a protein's molecular function. Indeed, detailed studies of individual genes 


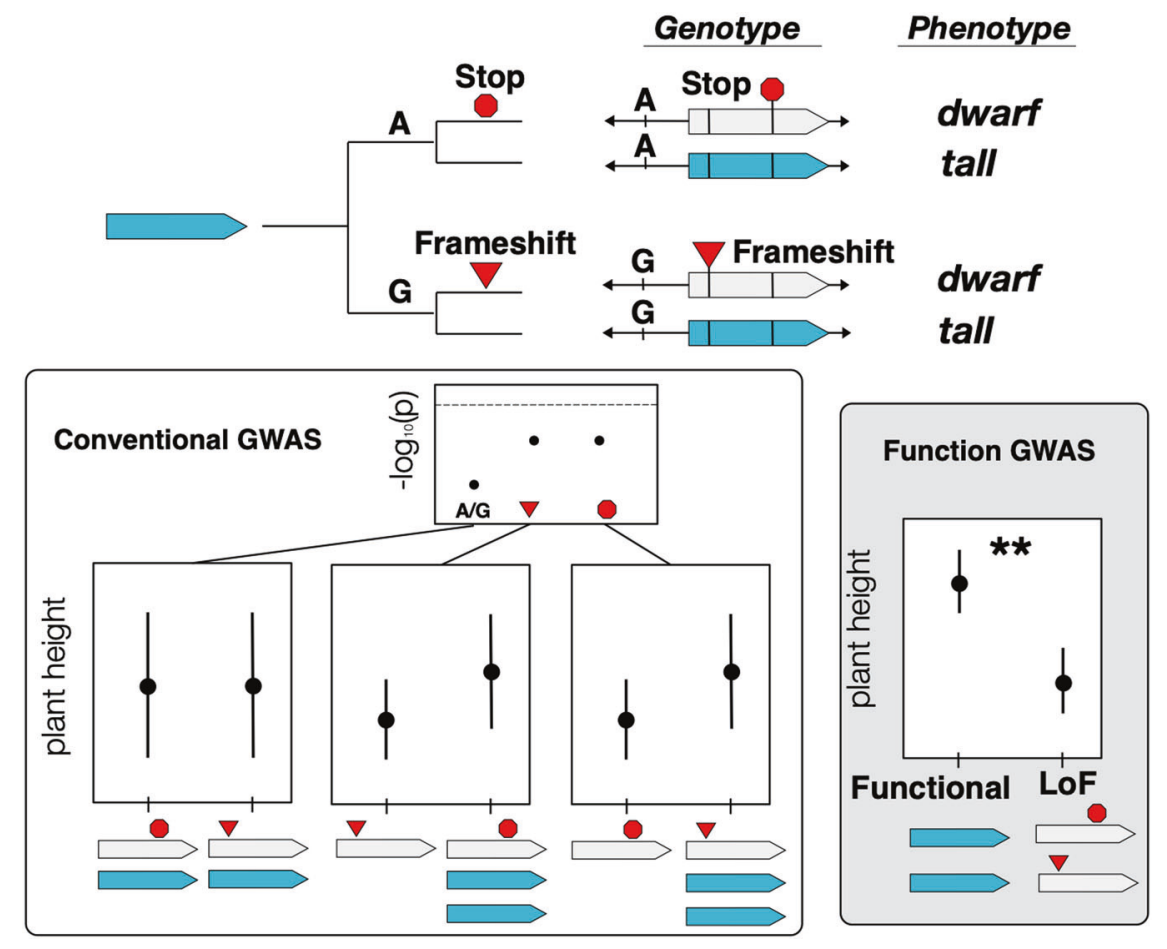

Fig. 6 Imagined case in which independent loss-of-function (LoF) alleles give rise to adaptive dwarf phenotypes inspired by (Barboza et al. 2013). In this case, a premature stop codon and a frameshift mutation have arisen in alternative genetic backgrounds distinguished here by a nearby SNP (top). Conventional, functionally agnostic GWAS (bottom left) tests for association between individual variants and the trait of interest, in this case plant height, fail because none of the individual variants capture the functionally definitive variation (indicated by p-values below the significance threshold marked by the dashed line). An alternative approach, functional GWAS, first annotates variants according to predicted functional effects, then defines alleles as functional or non-functional. This corrects for allelic heterogeneity when testing for allele-trait associations and results in a significant allele trait association (bottom right). have uncovered non-synonymous loss-of-function variants (Sasaki et al. 2002; Barboza et al. 2013; Zhang and Jiménez-Gómez 2020; Song et al. 2020, 2014) suggesting the maintenance of extensive cryptic (not easily identified as loss-of-function from standard annotation pipelines) genetic loss-of-function variation within populations (Table 1). But identifying non-synonymous mutations which result in lossof-function among the numerous non-synonymous polymorphisms is difficult since experimental validation of the functional impacts for every non-synonymous variant is infeasible at genomic scales. Instead, predictions of functional impact must be predicted by more sophisticated methods (Tang and Thomas 2016), such as quantifying changes in the chemical properties of amino acid substitutions (Grantham 1974), sequence homology (Ng and Henikoff 2001), known phenotypic effects (Schwarz et al. 2010), the context of known domains and protein structures, or through integration of multiple methods with tools such as CADD (Kircher et al. 2014; Tang and Thomas 2016). Emerging statistical machine learning approaches, such as unsupervised latent variable models can also detect otherwise cryptic loss of function caused by non-synonymous substitutions (Riesselman et al. 2018). The effect of coding sequence variation on protein folding may also be predicted from deep learning approaches, such as AlphaFold (Senior et al. 2020). Beyond mutations affecting coding sequence, eliminating gene expression could also cause loss of function (Albalat and Cañestro 2016), but identifying such mutations is challenging and validation at genomic scales is currently difficult. However, as with non-synonymous substitutions, advances in machine learning have also led to models that can predict functional consequences of noncoding variants (Zhou and Troyanskaya 2015). These methods can also be used to predict variants causing loss of gene expression. The application of these new tools presents a path forward for a new generation of functionally explicit analyses of genomic diversity. More broadly, a major goal of modern biology is to predict molecular function from genomic sequence data. The study of adaptive loss-offunction alleles could serve as a model class of genetic variation to spearhead this effort.

The accurate prediction of allele function from population genomic data assumes that researchers have complete information about what is functional and about sample sequence diversity. The genomes of reference genotypes used as the basis of comparison for whole genome re- 
sequencing projects can themselves already harbor loss-offunction alleles, obfuscating definitions of "functional" and therefore loss of function as well. For example, the standard A. thaliana reference is based on the genome of the Col-0 genotype, which is known to harbor an adaptive loss-offunction variant in the vernalization gene FRIGIDA (Johanson et al. 2000). Therefore, to study natural functional variation in this locus, Zhang and Jiménez-Gómez (2020) computationally swapped the reference sequence at this locus with a known functional allele and remapped public short read sequencing data to discover novel loss-offunction variants. Such scenarios at genome-wide scales motivate ongoing efforts to generate and annotate multiple reference genomes for a given species (Michael et al. 2018; Sun et al. 2018; Yang et al. 2019; Jiao and Schneeberger 2020; Zhou et al. 2020; Liu et al. 2020; Michael and VanBuren 2020; Li et al. 2020) to be used as a basis of comparison to describe broader population genetic diversity. Furthermore, most population-scale genome sequencing has been completed using short read sequencing technologies $(</=300$ base pairs), which require greater depth to reliably detect small insertions and deletions (compared to single nucleotide polymorphisms) and may be unable to reliably detect large insertions, deletions, and other structural variants altogether (Kishikawa et al. 2019). These unseen variants could be a considerable source of loss-of-function alleles in natural populations, and the difficulty to detect them (Fig. 3) might imply that many adaptive loss-of-function alleles are yet to be discovered. Thus, most assessments of population genetic variation are still limited to only a fraction of functional allelic diversity. Third-generation sequencing technologies are therefore facilitating more complete characterizations of allelic diversity (Alonge et al. 2020; Liu et al. 2020). Precise characterization of alleles at functional molecular resolutions is greater than being a technical challenge for studying sequence variation-it is essential for making sense of genomic sequence data through the lens of classic population genetics theory. We will see how this is exemplified in cases of adaptive loss-of-function alleles, whose high effective mutation rate leads to a breakdown of the assumptions underlying standard approaches used to detect signatures of selection and genotype to phenotype mapping.

\section{Many ways to break a gene: quantifying allelic heterogeneity}

A characteristic feature of genes experiencing adaptive loss of function is the existence of multiple functionally equivalent variants. To understand the extent of such variation, we can quantify and predict allelic heterogeneity, the phenomenon where multiple independent molecular variants exist that produce functionally analogous alleles of a given locus (Haldane 1927; Kimura 1962; Wilson Petrov et al. 2014; Ralph and Coop 2015). Assuming a constant effective population size $\left(\boldsymbol{N}_{\boldsymbol{e}}\right)$, mutation rate of an adaptive allele $(\boldsymbol{u})$, and selection coefficient on that adaptive allele $(s)$, the expected number of mutationally independent alleles of the locus that will be observed in a population at the moment of allele fixation $(\boldsymbol{k})$, a unit of allelic heterogeneity, is predicted (Wilson Petrov et al. 2014) as:

$k=2 \log \left(N_{e} S\right) N_{e} u$

The expected number of independent alleles at fixation is directly correlated with the mutation rate (Eq. 1, Fig. 4). Early studies of mutation rate quantified the frequency at which mutations gave rise to a particular allelic state, defined by its phenotypic effect. These studies often reported phenotypic mutation rate estimates ranging from $10^{-4}$ to $10^{-6}$ mutations (change in phenotype) per generation (Muller 1928; Haldane 1933; Rhoades 1941; Stadler 1946, 1948). Estimates of molecular mutation rates at the DNA sequence level are generally orders of magnitude lower: $10^{-8}$ to $10^{-10}$ mutations (change in sequence) per site per generation (Lynch et al. 2016). A partial explanation for the discrepancy between the range of phenotypic and molecular mutation rate is the obvious fact that many different molecular mutations can give rise to the same phenotypically/functionally effective allele type. Loss-offunction mutations exemplify this reality. Because there are hundreds or thousands of different molecular mutations that can produce a suite of analogous loss-of-function alleles (e.g., any premature stop codon or differently sized deletions along much of the coding region of a gene), the aggregated mutation rate for loss of function is expected to be orders of magnitude greater than the molecular mutation rate. At such high effective mutation rates we should predict, given biologically reasonable population sizes and selection coefficients, the existence of considerable allelic heterogeneity (Fig. 4a), which appears consistent with empirical observations (Figs. 1 and 4b).

\section{Mixed signals in signatures of selection}

Early genetics employed a functionally definitive concept of an allele. Alleles were treated as local units of inheritance based on their functional effect, observed at the phenotypic level (e.g., Rhoades 1938). As such, at locus a experiencing adaptive loss of function, the (potentially multiple) variants causing the adaptive trait should act collectively as a single allele, even if due to independent mutational events (Pennings and Hermisson 2006a, b). If, for example, this functionally identical set of variants experiences positive selection, it behaves like a single allele according to 
predictions of classic population genetic theory (Orr 2005) -increasing in frequency to fixation (Fig. 4a, inset). Indeed, foundational models of population genetics (Haldane 1927) accommodate recurrent mutation and predict that adaptation will often involve multiple independent mutational origins given realistic population sizes, selection coefficients, and mutation rates (Eq. 1, Fig. 4a). But if we encounter such cases through analyses of DNA sequence alone, we may be troubled to find that the sequence variants only exhibit the expected evolutionary dynamics of classical alleles when considered as aggregated functional units, but not when analyzed individually (Remington 2015).

Scenarios like these have been extensively studied in a broad manner, in order to detect signatures of soft sweeps of multiple independent variants. A number of approaches have been developed to study soft sweeps. These generally do not attempt to classify variants into functional allele categories but instead look for evidence of increased frequency of multiple rather than single haplotypes in a functionally agnostic fashion (Schrider and Kern 2016; Hermisson and Pennings 2017; Harris et al. 2018; Mughal and DeGiorgio 2019; Stern et al. 2019; Hartfield and Bataillon 2020; Garud et al. 2020). Nevertheless, it is interesting to note that extensive research into soft sweeps came only after increasing evidence of the potential adaptive value of loss-of-function alleles had been published (Pennings and Hermisson 2006a, b 2006). In contrast, hard sweeps of a single adaptive variant were described during the era predominated by the view that loss-of-function mutations were necessarily deleterious, and adaptation could only proceed through mutationally rare gain-of-function alleles (Maynard Smith and Haigh 1974). Such historical dynamics speak to the interconnectedness, intentional or otherwise, between ideas about the functional molecular basis of adaptation and advances in the development of population genetic models and theories.

Unfortunately, population genetic statistics based on the expectation that adaptive alleles are mutationally rare perform poorly when this assumption is violated. For example, statistics based on the site frequency spectrum such as Tajima's D do not deviate from neutral expectations in a predictable fashion for adaptive alleles with multiple mutational origins (Pennings and Hermisson 2006a). Similarly, statistics based on linkage disequilibrium around adaptive loci, though they tend to perform better for soft sweeps, also appear neutral if the number of mutational origins of an adaptive allele is high enough (Hermisson and Pennings 2017). For adaptive loss of function, this may often be the case. More generalized methods of detecting soft selective sweeps from independent mutational origins, such as the H12 statistic developed by Garud and colleagues (Garud et al. 2015) might be useful for detecting adaptive loss of function. The reciprocal is also true-known cases of adaptive loss of function could serve as valuable models for testing the limits of test statistics intended to detect soft sweeps.

More functionally explicit statistics of allelic variation are now possible because of the availability of whole genomic sequence data. However, the application of functional test statistics to genes experiencing putatively adaptive loss-of-function can yield surprising results. For example, the Neutrality Index (NI) (McDonald and Kreitman 1991; Rand and Kann 1996) estimates histories of selection by comparing rates of within-species polymorphism and between-species divergence. It is more functionally explicit than many population genetics statistics-comparing putatively functionally impactful (non-synonymous) versus silent (synonymous) variation. Where $P_{n}=$ nonsynonymous polymorphism, $P_{s}=$ synonymous polymorphism, $D_{n}=$ non-synonymous divergence, $D_{s}=$ synonymous divergence

$N I=\left(P_{n} / P_{s}\right) /\left(D_{n} / D_{s}\right)$

Traditional interpretations of the results are based on the assumption that adaptive variants will become fixed and therefore be observed as diverged $\left(D_{n}\right)$ from related species rather than polymorphic $\left(P_{n}\right)$ within the study species. When genes putatively experiencing adaptive loss of function are investigated, they are often found to have high $N I$ values (Le Corre et al. 2002; Flowers et al. 2009; Will et al. 2010; Rose et al. 2012; Monroe et al. 2016), a pattern that seems paradoxical given that high $N I$ values are commonly interpreted as evidence of purifying selection (Weinreich and Rand 2000). But when considered with the knowledge that non-synonymous variants can themselves cause loss of function, and given the likely independent mutational origins of loss of function, this result is consistent with expectations of an enrichment of non-synonymous polymorphism in genes with both high frequency of loss of function and high NI (Fig. 5).

Increasingly functionally precise statistics such as the sum frequencies of losses of function in a given gene across all variants (Albalat and Cañestro 2016) might better describe loss-of-function alleles than functionally agnostic test statistics or descriptions of individual variants. Accelerations in whole genome sequencing technologies and improved capacity to classify previously cryptic loss-offunction variants may facilitate a new generation of functionally definitive population genetic models and methods. This would not only be valuable for improving the capacity to understand the forces shaping intraspecific loss-of-function, but more generally promote a re-synthesis between studies of molecular sequence variation and the functionbased conception of alleles from early population genetic theory. 


\section{Functionally explicit genotype-to-phenotype mapping}

To identify genes contributing to adaptive phenotypic variation, Genome Wide Association (GWA) scans in natural populations have become a popular alternative to conventional mapping in an experimental population derived from a bi-parental cross. GWA is normally implemented by testing for associations between individual DNA sequence variants in a population and the phenotype (or environmental gradient) of interest. This statistical framework can fail to detect causal loci in the presence of allelic heterogeneity because none of the individual variants are linked to a single causal variant-an assumption of single-locus twoallele population genetic models (Korte and Farlow 2013). This problem is exemplified by loss of function variation in which, with a few notable exceptions (Song et al. 2020), allelic heterogeneity is expected to be the norm (Pennings and Hermisson 2006a, b).

The case of the GA-20 oxidase gene in plants provides a useful illustration of these challenges. This well-studied gene is involved in gibberellin biosynthesis and loss of function produces semi-dwarf phenotypes in wild plants and crop varieties of the Green Revolution (Fig. 1f) (Spielmeyer et al. 2002; Sasaki et al. 2002; Jia et al. 2009; Barboza et al. 2013). While functional experiments have demonstrated that loss of this gene causes considerable reduction in plant height, and investigations of natural molecular variation in A. thaliana identified cases of likely loss-of-function differences between genotypes, a conventional GWA looking for loci explaining variation in plant height failed to detect the GA-20 oxidase locus in $A$. thaliana (Barboza et al. 2013). However, when all of the genotypes with predicted loss-of-function variants were collapsed into a single allele state and their heights contrasted with the genotypes containing predicted functional variants, the known highly significant effect on plant height was detected (Barboza et al. 2013). Without previous knowledge that this gene plays an important role in plant height, it would have been missed by conventional GWA. This experiment provides a cautionary tale as to how conventional GWA approaches can fail in the presence of allelic heterogeneity at causal loci. It also highlights the power of functionally explicit GWA approaches based on population genetic models that allow for allelic heterogeneity-using predictions about functional effects of individual variants to collapse variants into allele classes (in this case, loss-of-function vs functional) so that a functionally explicit contrast can be made (Fig. 6).

To date, such a framework has been primarily used in the study of rare variants (Wu et al. 2011; Pan and Shen 2011; Zhang et al. 2017) to identify rare deleterious loss-offunction alleles associated with disease phenotypes in humans (Zuk et al. 2014) but it could also be used to find beneficial and adaptive loss of function as well. For example, loss of function in SLC3OA8 was found to be strongly associated with decreased risk of type 2 diabetes when all loss-of-function variants were collapsed into a single allele state (Flannick et al. 2014) (Fig. 1a), thus identifying its protein product as a promising therapeutic target to treat diabetes (Dwivedi et al. 2019). With population whole-genome-sequence data becoming available in model and non-model species, this approach can now be readily applied by evolutionary biologists at genome wide scales to discover loss-of-function alleles contributing to phenotypic evolution in populations (Monroe et al. 2020).

A functionally explicit GWA framework may have value beyond scanning genomes for causal loss-of-function alleles. More broadly, it reflects a step toward representing genetic diversity as a matrix of functionally relevant genetic alleles rather than a matrix of DNA sequence variants. While loss of function is currently the easiest allele state to classify, we anticipate that more nuanced and precise allele categories can be identified through analyses of population genomic diversity with advances in sequence annotation. Ideally, these categories would specify the activity of an allele along a scale that reflects Muller's original categories of amorphic, hypomorphic, hypermorphic, antimorphic, and neomorphic states (Muller 1932). In addition to facilitating discovery of causal loci, functionally explicit methods of population genomics could be useful for predicting quantitative traits (i.e., genomic prediction) and address the problem of missing heritabilities (Manolio et al. 2009) that has frustrated modern geneticists for over a decade (Eichler et al. 2010).

\section{Outlook and concluding remarks}

Loss-of-function alleles were once often held up as a paragon of deleterious genetic variation. Today a more nuanced appreciation for their potential role in adaptation has emerged. This new paradigm inspires investigations into deeper questions about the causes and consequences of adaptation by genetic loss of function. For example: Do species or populations differ in their capacity to adapt via loss of function, and if so, why? Does the high effective mutation rate of loss-of-function alleles lead to bias in the probabilities of different evolutionary outcomes? What is the contribution of adaptive loss of function to the phenomena of antagonistic pleiotropy and reproductive isolation? How does adaptation by loss of function affect long term evolutionary trajectories of populations and future evolvability? Ongoing technical breakthroughs promise to scale up the study of loss-of-function alleles experiencing positive selection for population genomic research to 
address these questions. More broadly, these lines of research provide paths toward advancing tools and concepts that facilitate a continued synthesis between functional molecular genomics and classic population genetic theory.

Acknowledgements We would like to thank Wim Soppe, Alex Wong, Matthew Rutter, Michael Turelli and Andrew Whitehead for insights and feedback that improved this manuscript. We thank DBCLS (CC BY 4.0), CDC, Mae Melvin (Public Domain), Mogana Das Murtey and Patchamuthu Ramasamy (CC BY 3.0) Aomorikuma (CC BY 4.0) for images used in this manuscript. This work was supported by NSF Awards 1556262 to JKM and 1701918 to JGM, DFG ERA-CAPS $1001 \mathrm{G}+$ to DW, and the Max Planck Society.

\section{Compliance with ethical standards}

Conflict of interest The authors declare that they have no conflict of interest.

Publisher's note Springer Nature remains neutral with regard to jurisdictional claims in published maps and institutional affiliations.

Open Access This article is licensed under a Creative Commons Attribution 4.0 International License, which permits use, sharing, adaptation, distribution and reproduction in any medium or format, as long as you give appropriate credit to the original author(s) and the source, provide a link to the Creative Commons license, and indicate if changes were made. The images or other third party material in this article are included in the article's Creative Commons license, unless indicated otherwise in a credit line to the material. If material is not included in the article's Creative Commons license and your intended use is not permitted by statutory regulation or exceeds the permitted use, you will need to obtain permission directly from the copyright holder. To view a copy of this license, visit http://creativecommons. org/licenses/by/4.0/.

\section{References}

1001 Genomes Consortium (2016) 1135 genomes reveal the global pattern of polymorphism in arabidopsis thaliana. Cell 166:481-491

Aird SD, Arora J, Barua A, Qiu L, Terada K, Mikheyev AS (2017) Population genomic analysis of a pitviper reveals microevolutionary forces underlying venom chemistry. Genome Biol Evol 9:2640-2649

Albalat R, Cañestro C (2016) Evolution by gene loss. Nat Rev Genet 17:379-391

Alonge M, Wang X, Benoit M, Soyk S, Pereira L, Zhang L et al. (2020) Major Impacts of Widespread Structural Variation on Gene Expression and Crop Improvement in Tomato. Cell

Baggs E, Monroe JG, Thanki AS, O'Grady R, Schudoma C, Haerty W, et al. (2020) Convergent loss of an EDS1/PAD4 signaling pathway in several plant lineages reveals co-evolved components of plant immunity and drought response. Plant Cell 32:2158-2177

Barboza L, Effgen S, Alonso-Blanco C, Kooke R, Keurentjes JJB, Koornneef $\mathrm{M}$ et al. (2013) Arabidopsis semidwarfs evolved from independent mutations in GA20ox1, ortholog to green revolution dwarf alleles in rice and barley. Proc Natl Acad Sci USA 110:15818-15823

Bi C, Lu N, Han T, Huang Z, Chen J-Y, He C et al. (2020) Wholegenome resequencing of twenty branchiostoma belcheri individuals provides a brand-new variant dataset for branchiostoma. Biomed Res Int 2020:3697342
Blomme T, Vandepoele K, De Bodt S, Simillion C, Maere S, Van de Peer Y (2006) The gain and loss of genes during 600 million years of vertebrate evolution. Genome Biol 7:R43

Buckley RM, Davis BW, Brashear WA, Farias FHG (2020). A new domestic cat genome assembly based on long sequence reads empowers feline genomic medicine and identifies a novel gene for dwarfism. bioRxiv

Chen J, Wu J, Zhang P, Dong C, Upadhyaya NM, Zhou Q et al (2019) De Novo genome assem comp genomics barley leaf rust pathog puccinia hordei identifies candidates three avirulence genes G3 9:3263-3271

Chen L-Y, VanBuren R, Paris M, Zhou H, Zhang X, Wai CM et al. (2019) The bracteatus pineapple genome and domestication of clonally propagated crops. Nat Genet 51:1549-1558

Claessens A, Affara M, Assefa SA, Kwiatkowski DP, Conway DJ (2017) Culture adaptation of malaria parasites selects for convergent loss-of-function mutants. Sci Rep. 7:41303

Cook DE, Zdraljevic S, Roberts JP, Andersen EC (2017) CeNDR, the Caenorhabditis elegans natural diversity resource. Nucleic Acids Res 45:D650-D657

Dahiya S, Beier UH, Wang L, Han R, Jiao J, Akimova T et al. (2020) HDAC10 deletion promotes Foxp3+ T-regulatory cell function. Sci Rep. 10:424

Du X, Huang G, He S, Yang Z, Sun G, Ma X et al. (2018) Resequencing of 243 diploid cotton accessions based on an updated A genome identifies the genetic basis of key agronomic traits. Nat Genet 50:796-802

Dwivedi OP, Lehtovirta M, Hastoy B, Chandra V, Krentz NAJ, Kleiner S et al. (2019) Loss of ZnT8 function protects against diabetes by enhanced insulin secretion. Nat Genet 51:1596-1606

Eichler EE, Flint J, Gibson G, Kong A, Leal SM, Moore JH et al. (2010) Missing heritability and strategies for finding the underlying causes of complex disease. Nat Rev Genet 11:446-450

Engel W, Schmidtke J, Vogel W, Wolf U (1973) Genetic polymorphism of lactate dehydrogenase isoenzymes in the carp (Cyprinus carpio) apparently due to a 'null allele'. Biochem Genet 8:281-289

Flannick J, Thorleifsson G, Beer NL, Jacobs SBR, Grarup N, Burtt NP et al. (2014) Loss-of-function mutations in SLC30A8 protect against type 2 diabetes. Nat Genet 46:357-363

Flowers JM, Hanzawa Y, Hall MC, Moore RC, Purugganan MD (2009) Population genomics of the Arabidopsis thaliana flowering time gene network. Mol Biol Evol 26:2475-2486

Fry AE, Ghansa A, Small KS, Palma A, Auburn S, Diakite M et al. (2009) Positive selection of a CD36 nonsense variant in subSaharan Africa, but no association with severe malaria phenotypes. Hum Mol Genet 18:2683-2692

Garud NR, Messer PW, Buzbas EO, Petrov DA (2015) Recent selective sweeps in North American Drosophila melanogaster show signatures of soft sweeps. PLoS Genet 11:e1005004

Garud NR, Messer PW, Petrov DA (2020) Detection of hard and soft selective sweeps from Drosophila melanogaster population genomic data. bioRxiv

Gerdol M, Moreira R, Cruz F, Gómez-Garrido J, Vlasova A, Rosani U et al. (2020) Massive gene presence-absence variation shapes an open pan-genome in the Mediterranean mussel. Genome Biol 21:275

Gordon SP, Contreras-Moreira B, Woods DP, Des Marais DL, Burgess D, Shu $\mathrm{S}$ et al. (2017) Extensive gene content variation in the Brachypodium distachyon pan-genome correlates with population structure. Nat Commun 8:2184

Gramazio P, Yan H, Hasing T, Vilanova S, Prohens J, Bombarely A (2019) Whole-genome resequencing of seven eggplant (Solanum melongena) and one wild relative ( $\mathrm{S}$. incanum) accessions provides new insights and breeding tools for eggplant enhancement. Front Plant Sci 10:1220 
Grantham R (1974) Amino acid difference formula to help explain protein evolution. Science 185:862-864

Griesmann M, Chang Y, Liu X, Song Y, Haberer G, Crook MB et al. (2018) Phylogenomics reveals multiple losses of nitrogen-fixing root nodule symbiosis. Science 361 :eaat 1743

Gu L, Wang F, Lin Z, Xu T, Lin D, Xing M et al. (2020) Genetic characteristics of Jiaji Duck by whole genome re-sequencing. PLOS ONE 15:e0228964

Haldane JBS (1927) A mathematical theory of natural and artificial selection, Part V: selection and mutation. Math Proc Camb Philos Soc 23:838-844

Haldane JBS (1933) The part played by recurrent mutation in evolution. Am Nat 67:5-19

Harris AM, Garud NR, DeGiorgio M (2018) Detection and classification of hard and soft sweeps from unphased genotypes by multilocus genotype identity. Genetics 210:1429-1452

Hartfield M, Bataillon T (2020) Selective sweeps dominance inbreeding. G3 10:1063-1075

Hermisson J, Pennings PS (2017) Soft sweeps and beyond: understanding the patterns and probabilities of selection footprints under rapid adaptation (J Kelley, Ed.). Methods Ecol Evol 8:700-716

Hermsen R, de Ligt J, Spee W, Blokzijl F, Schäfer S, Adami E et al. (2015) Genomic landscape of rat strain and substrain variation. BMC Genomics 16:357

Huang W, Massouras A, Inoue Y, Peiffer J, Ràmia M, Tarone AM et al. (2014) Natural variation in genome architecture among 205 Drosophila melanogaster Genetic Reference Panel lines. Genome Res 24:1193-1208

Huelsmann M, Hecker N, Springer MS, Gatesy J, Sharma V, Hiller M (2019) Genes lost during the transition from land to water in cetaceans highlight genomic changes associated with aquatic adaptations. Sci Adv 5:eaaw6671

Iqbal N, Liu X, Yang T, Huang Z, Hanif Q, Asif M et al. (2019) Genomic variants identified from whole-genome resequencing of indicine cattle breeds from Pakistan. PLoS ONE 14:e0215065

Jacq C, Miller JR, Brownlee GG (1977) A pseudogene structure in 5S DNA of Xenopus laevis. Cell 12:109-120

Jensen JD (2014) On the unfounded enthusiasm for soft selective sweeps. Nat Commun 5:5281

Jiao W-B, Schneeberger K (2020) Chromosome-level assemblies of multiple Arabidopsis genomes reveal hotspots of rearrangements with altered evolutionary dynamics. Nat Commun 11:1-10.

Jia Q, Zhang J, Westcott S, Zhang X-Q, Bellgard M, Lance R et al. (2009) GA-20 oxidase as a candidate for the semidwarf gene sdw1/denso in barley. Funct Integr Genomics 9:255-262

Jin M, Liu H, He C, Fu J, Xiao Y, Wang Y et al. (2016) Maize pantranscriptome provides novel insights into genome complexity and quantitative trait variation. Sci Rep. 6:18936

Johanson U, West J, Lister C, Michaels S, Amasino R, Dean C (2000) Molecular analysis of FRIGIDA, a major determinant of natural variation in Arabidopsis flowering time. Science 290:344-347

Jones EW (1972) Fine structure analysis of the ade3 Locus in SACCHAROMYCES CEREVISIAE. Genetics 70:233-250

Karczewski KJ, Francioli LC, Tiao G, Cummings BB, Alföldi J, Wang $\mathrm{Q}$ et al. (2020) The mutational constraint spectrum quantified from variation in 141,456 humans. Nature 581:434-443

Kimura M (1962) On the probability of fixation of mutant genes in a population. Genetics 47:713-719

Kircher M, Witten DM, Jain P, O'Roak BJ, Cooper GM, Shendure J (2014) A general framework for estimating the relative pathogenicity of humangenetic variants. Nat Genet 46:310-315

Kishikawa T, Momozawa Y, Ozeki T, Mushiroda T, Inohara H, Kamatani Y et al. (2019) Empirical evaluation of variant calling accuracy using ultra-deepwhole-genome sequencing data Sci Rep $9: 1784$
Koenig D, Hagmann J, Li R, Bemm F, Slotte T, Neuffer B, et al. (2019) Long-term balancing selection drives evolution of immunity genes in Capsella. Elife 8:e43606

Koepfli K-P, Tamazian G, Wildt D, Dobrynin P, Kim C, Frandsen PB et al. (2019) Whole genome sequencing and re-sequencing of the sable antelope (Hippotragus niger): a resource for monitoring diversity in ex situ and in situ populations. G3 9:1785-1793

Korte A, Farlow A (2013) The advantages and limitations of trait analysis with GWAS: a review. Plant methods 9:1-9

Kulkarni RN, Brüning JC, Winnay JN, Postic C, Magnuson MA, Kahn CR (1999) Tissue-specific knockout of the insulin receptor in pancreatic beta cells creates an insulin secretory defect similar to that in type 2 diabetes. Cell 96:329-339

Kvitek DJ, Sherlock G (2013) Whole genome, whole population sequencing reveals that loss of signaling networks is the major adaptive strategy in a constant environment. PLoS Genet 9:e1003972

Ladner JT, Wiley MR, Mate S, Dudas G, Prieto K, Lovett S et al. (2015) Evolution and spread of Ebola virus in Liberia, 2014-2015. Cell host \& microbe 18:659-669

Lazaro JEH, Bascos NAD, Tablizo FA, Abes NS, Paynaganan RID, Miguel MA et al. (2019) Genome-wide Analysis for Variants in Philippine Trypanosoma evansi Isolates with Varying Drug Resistance Profiles. Philippine Journal of Science 148(S1):219-233

Le Corre V, Roux F, Reboud X (2002) DNA polymorphism at the FRIGIDA gene in Arabidopsis thaliana: extensive nonsynonymous variation is consistent with local selection for flowering time. Mol Biol Evol 19:1261-1271

Libert F, Cochaux P, Beckman G, Samson M, Aksenova M, Cao A et al. (1998) The $\Delta$ ccr5 mutation conferring protection against HIV-1 in Caucasian populations has a single and recent origin in northeastern Europe. Hum Mol Genet 7:399-406

Li Y, Colleoni C, Zhang J, Liang Q, Hu Y, Ruess H et al. (2018) Genomic analyses yield markers for identifying agronomically important genes in potato. Mol Plant 11:473-484

Liu J, Seetharam AS, Chougule K, Ou S, Swentowsky KW, Gent JI et al. (2020) Gapless assembly of maize chromosomes using long-read technologies. Genome Biol 21:121

Li C, Xiang X, Huang Y, Zhou Y, An D, Dong J et al. (2020) Longread sequencing reveals genomic structural variations that underlie creation of quality protein maize. Nat Commun 11:17

Love-Gregory L, Sherva R, Schappe T, Qi J-S, McCrea J, Klein S et al. (2011) Common CD36 SNPs reduce protein expression and may contribute to a protective atherogenic profile. Hum Mol Genet 20:193-201

Lynch M, Ackerman MS, Gout J-F, Long H, Sung W, Thomas WK et al. (2016) Genetic drift, selection and the evolution of the mutation rate. Nat Rev Genet 17:704-714

MacArthur DG, Balasubramanian S, Frankish A, Huang N, Morris J, Walter K et al. (2012) A systematic survey of loss-of-function variants in human protein-coding genes. Science 335:823-828

Mace ES, Tai S, Gilding EK, Li Y, Prentis PJ, Bian L et al. (2013) Whole-genome sequencing reveals untapped genetic potential in Africa's indigenous cereal crop sorghum. Nat Commun 4:2320

Manolio TA, Collins FS, Cox NJ, Goldstein DB, Hindorff LA, Hunter DJ et al. (2009) Finding the missing heritability of complex diseases. Nature 461:747-753

McDonald JH, Kreitman M (1991) Adaptive protein evolution at the Adh locus in Drosophila. Nature 351:652-654

McGowen MR, Tsagkogeorga G, Williamson J, Morin PA, Rossiter SJ (2020). Positive selection and inactivation in the vision and hearing genes of cetaceans. Mol Biol Evol 37:2069-2083

McInerney JO, McNally A, O'Connell MJ (2017) Why prokaryotes have pangenomes. Nat Microbiol 2:17040

McLean CY, Reno PL, Pollen AA, Bassan AI, Capellini TD, Guenther $\mathrm{C}$ et al. (2011) Human-specific loss of regulatory DNA and the evolution of human-specific traits. Nature 471:216-219 
Messer PW, Petrov DA (2013) Population genomics of rapid adaptation by soft selective sweeps. Trends Ecol Evol 28:659-669

Michael TP, Jupe F, Bemm F, Motley ST, Sandoval JP, Lanz C et al. (2018) High contiguity Arabidopsis thaliana genome assembly with a single nanopore flow cell. Nat Commun 9:541

Michael TP, VanBuren R (2020) Building near-complete plant genomes. Curr Opin Plant Biol 54:26-33

Monroe JG, Arciniegas JP, Moreno JL, Sánchez F, Sierra S, Valdes S et al. (2020) The lowest hanging fruit: Beneficial gene knockouts in past, present, and future crop evolution. Curr Plant Biology 24:100185

Monroe JG, McGovern C, Lasky JR, Grogan K, Beck J, McKay JK (2016) Adaptation to warmer climates by parallel functional evolution of $\mathrm{CBF}$ genes in Arabidopsis thaliana. Molecular ecology 25:3632-3644

Monroe JG, Powell T, Price N, Mullen JL, Howard A, Evans K et al. (2018) Drought adaptation in Arabidopsis thaliana by extensive genetic loss-of-function. Elife 7

Monroe JG, Srikant T, Carbonell-Bejerano P, Exposito-Alonso M, Weng M-L, Rutter MT et al. (2020) Mutation bias shapes gene evolution in Arabidopsis thaliana. BioRxiv

Moyers BT, Morrell PL, McKay JK (2018) Genetic costs of domestication and improvement. J Hered 109:103-116

Mughal MR, DeGiorgio M (2019) Localizing and classifying adaptive targets with trend filtered regression. Mol Biol Evol 36:252-270

Muller HJ (1928) The measurement of gene mutation rate in drosophila, its high variability, and its dependence upon temperature. Genetics 13:279-357

Muller HJ (1932) Further studies on the nature and causes of gene mutations. Proc Int Congr Genet 6:213-255

Murray AW (2020) Can gene-inactivating mutations lead to evolutionary novelty? Curr Biol 30:R465-R471

Nei M, Roychoudhury AK (1973) Probability of fixation and mean fixation time of an overdominant mutation. Genetics 74:371-380

Ng PC, Henikoff S (2001) Predicting deleterious amino acid substitutions. Genome Res 11:863-874

Olson MV (1999) When less is more: gene loss as an engine of evolutionary change. Am J Hum Genet 64:18-23

Orr HA (2005) The genetic theory of adaptation: a brief history. Nature Reviews Genetics 6:119-127

Pan W, Shen X (2011) Adaptive tests for association analysis of rare variants. Genet Epidemiol 35:381-388

Pennings PS, Hermisson J (2006a) Soft sweeps II-molecular population genetics of adaptation from recurrent mutation or migration. Mol Biol Evol 23:1076-1084

Pennings PS, Hermisson J (2006b) Soft sweeps III: the signature of positive selection from recurrent mutation. PLoS Genet 2:e186

Peter J, De Chiara M, Friedrich A, Yue J-X, Pflieger D, Bergström A et al. (2018) Genome evolution across 1011 Saccharomyces cerevisiae isolates. Nature 556:339-344

Piot A, Prunier J, Isabel N, Klápště J, El-Kassaby YA, Villarreal Aguilar JC et al. (2019) Genomic diversity evaluation of populus trichocarpa germplasm for rare variant genetic association studies. Front Genet 10:1384

Plassais J, Kim J, Davis BW, Karyadi DM, Hogan AN, Harris AC et al. (2019) Whole genome sequencing of canids reveals genomic regions under selection and variants influencing morphology. Nat Commun 10:1489

Ralph PL, Coop G (2015) Convergent evolution during local adaptation to patchy landscapes. PLoS Genet 11:e1005630

Ramu P, Esuma W, Kawuki R, Rabbi IY, Egesi C, Bredeson JV et al. (2017) Cassava haplotype map highlights fixation of deleterious mutations during clonal propagation. Nat Genet 49:959-963

Rand DM, Kann LM (1996) Excess amino acid polymorphism in mitochondrial DNA: contrasts among genes from Drosophila, mice, and humans. Mol Biol Evol 13:735-748
Rayko M, Komissarov A (2020) Quality control of low-frequency variants in SARS-CoV-2 genomes. BioRxiv

Remington DL (2015) Alleles versus mutations: understanding the evolution of genetic architecture requires a molecular perspective on allelic origins. Evolution 69:3025-3038

Rhoades MM (1941) The genetic control of mutability in maize. Cold Spring Harb Symp Quant Biol 9:138-144

Rhoades MM (1938) Effect of the Dt Gene on the Mutability of the a (1) Allele in Maize. Genetics 23:377-397

Richards JK, Stukenbrock EH, Carpenter J, Liu Z, Cowger C, Faris JD et al. (2019) Local adaptation drives the diversification of effectors in the fungal wheat pathogen Parastagonospora nodorum in the United States. PLoS Genet 15:e1008223

Riesselman AJ, Ingraham JB, Marks DS (2018) Deep generative models of genetic variation capture the effects of mutations. Nat Methods 15:816-822

Rose L, Atwell S, Grant M, Holub EB (2012) Parallel loss-of-function at the RPM1 bacterial resistance locus in Arabidopsis thaliana. Front Plant Sci 3:287

Sasaki A, Ashikari M, Ueguchi-Tanaka M, Itoh H, Nishimura A, Swapan D et al. (2002) A mutant gibberellin-synthesis gene in rice. Nature 416:701-702

Schrider DR, Kern AD (2016) S/HIC: robust identification of soft and hard sweeps using machine learning. PLoS Genet 12:e1005928

Schwarz JM, Rödelsperger C, Schuelke M, Seelow D (2010) MutationTaster evaluates disease-causing potential of sequence alterations. Nat Methods 7:575-576

Sharma V, Hecker N, Roscito JG, Foerster L, Langer BE, Hiller M (2018) A genomics approach reveals insights into the importance of gene losses for mammalian adaptations. Nat Commun 9:1215

Senior AW, Evans R, Jumper J, Kirkpatrick J, Sifre L, Green T et al. (2020) Improved protein structure prediction using potentials from deep learning. Nature 577:706-710

Maynard Smith J (1970) Natural selection and the concept of a protein space. Nature 225:563-564

Maynard Smith J, Haigh J (1974) The hitch-hiking effect of a favourable gene. Genet Res 23:23-35

Sollars ESA, Harper AL, Kelly LJ, Sambles CM, Ramirez-Gonzalez RH, Swarbreck D et al. (2017) Genome sequence and genetic diversity of European ash trees. Nature 541:212-216

Song K, Nelson MR, Aponte J, Manas ES, Bacanu S-A, Yuan X et al. (2012) Sequencing of Lp-PLA2-encoding PLA2G7 gene in 2000 Europeans reveals several rare loss-of-function mutations. Pharmacogenomics J 12:425-431

Song D, Li L-S, Arsenault PR, Tan Q, Bigham AW, Heaton-Johnson KJ et al. (2014) Defective Tibetan PHD2 binding to p23 links high altitude adaptionto altered oxygen sensing. J Biol Chem 289:14656-14665

Song D, Navalsky BE, Guan W, Ingersoll C, Wang T, Loro E et al. (2020) Tibetan PHD2, an allele with loss-of-function properties. Proc Natl Acad Sci USA 117:12230-12238

Spielmeyer W, Ellis MH, Chandler PM (2002) Semidwarf (sd-1), 'green revolution' rice, contains a defective gibberellin 20oxidase gene. Proc Natl Acad Sci USA 99:9043-9048

Stadler LJ (1946) Spontaneous mutation at the R Locus in Maize. I. the aleurone-color and plant-color effects. Genetics 31:377-394

Stadler LJ (1948) Spontaneous mutation at the R Locus in Maize. II. Race differences in mutation rate. Am Nat 82:289-314

Stern AJ, Wilton PR, Nielsen R (2019) An approximate full-likelihood method for inferring selection and allele frequency trajectories from DNA sequence data. PLoS Genet 15:e1008384

Sun S, Zhou Y, Chen J, Shi J, Zhao H, Zhao H et al. (2018) Extensive intraspecific gene order and gene structural variations between Mo17 and other maize genomes. Nat Genet 50:1289-1295

Tang H, Thomas PD (2016) Tools for predicting the functional impact of nonsynonymous genetic variation. Genetics 203:635-647 
Thudi M, Khan AW, Kumar V, Gaur PM, Katta K, Garg V et al. (2016) Whole genome re-sequencing reveals genome-wide variations among parental lines of 16 mapping populations in chickpea (Cicer arietinum L.). BMC Plant Biol 16(Suppl 1): 10

Torkamaneh D, Laroche J, Valliyodan B, O'Donoughue L, Cober E, Rajcan I, ... \& Belzile F (2019) Soybean haplotype map (GmHapMap): A universal resource for soybean translational and functional genomics. BioRxiv, 534578

Updegraff BL, Zhou X, Guo Y, Padanad MS, Chen P-H, Yang C et al. (2018) Transmembrane protease TMPRSS11B promotes lung cancer growth by enhancing lactate export and glycolytic metabolism. Cell Rep 25:2223-2233.e6

van Velzen R, Holmer R, Bu F, Rutten L, van Zeijl A, Liu W et al. (2018) Comparative genomics of the nonlegume Parasponia reveals insights into evolution of nitrogen-fixing rhizobium symbioses. Proc Natl Acad Sci USA 115:E4700-E4709.

Wang W, Mauleon R, Hu Z, Chebotarov D, Tai S, Wu Z et al. (2018) Genomic variation in 3,010 diverse accessions of Asian cultivated rice. Nature 557:43-49

Wang X, Grus WE, Zhang J (2006) Gene losses during human origins. PLoS Biol 4:e52

Wang X-L, Shi W-P, Shi H-C, Lu S-C, Wang K, Sun C et al. (2016) Knockdown of TRIM65 inhibits lung cancer cell proliferation, migration and invasion: A therapeutic target in human lung cancer. Oncotarget 7:81527-81540

Wei W-S, Chen X, Guo L-Y, Li X-D, Deng M-H, Yuan G-J et al. (2018) TRIM65 supports bladder urothelial carcinoma cell aggressiveness by promoting ANXA2 ubiquitination and degradation. Cancer Lett 435:10-22

Weinreich DM, Rand DM (2000) Contrasting patterns of nonneutral evolution in proteins encoded in nuclear and mitochondrial genomes. Genetics 156:385-399

Will JL, Kim HS, Clarke J, Painter JC, Fay JC, Gasch AP (2010) Incipient balancing selection through adaptive loss of aquaporins in natural Saccharomyces cerevisiae populations. PLoS Genet 6: e1000893

Wilson BA, Petrov DA, Messer PW (2014) Soft selective sweeps in complex demographic scenarios. Genetics 198:669-684

Wolf YI, Koonin EV (2013) Genome reduction as the dominant mode of evolution. Bioessays 35:829-837

Wong A, Rodrigue N, Kassen R (2012) Genomics of adaptation during experimental evolution of the opportunistic pathogen Pseudomonas aeruginosa. PLoS Genet 8:e1002928

Wu D, Liang Z, Yan T, Xu Y, Xuan L, Tang J et al. (2019) Wholegenome resequencing of a worldwide collection of rapeseed accessions reveals the genetic basis of ecotype divergence. Mol Plant 12:30-43

Wu MC, Lee S, Cai T, Li Y, Boehnke M, Lin X (2011) Rare-variant association testing for sequencing data with the sequence kernel association test. Am J Hum Genet 89:82-93

Wu J, Wang L, Fu J, Chen J, Wei S, Zhang S et al. (2020) Resequencing of 683 common bean genotypes identifies yield component trait associations across a north-south cline. Nat Genet 52:118-125

Xanthopoulou A, Montero-Pau J, Mellidou I, Kissoudis C, Blanca J, Picó B et al. (2019) Whole-genome resequencing of Cucurbita pepo morphotypes to discover genomic variants associated with morphology and horticulturally valuable traits. Hortic Res 6:94

Xiang Y, Song B, Née G, Kramer K, Finkemeier I, Soppe WJJ (2016) Sequence polymorphisms at the REDUCED DORMANCY5 Pseudophosphatase Underlie Natural Variation in Arabidopsis Dormancy. Plant Physiol 171:2659-2670

Xiao L, Ptacek T, Osborne JD, Crabb DM, Simmons WL, Lefkowitz EJ et al. (2015) Comparative genome analysis of Mycoplasma pneumoniae. BMC Genomics 16:610

Xue C, Raveendran M, Harris RA, Fawcett GL, Liu X, White S et al. (2016) The population genomics of rhesus macaques (Macaca mulatta) based on whole-genome sequences. Genome Res 26:1651-1662

Xu Y-C, Niu X-M, Li X-X, He W, Chen J-F, Zou Y-P et al. (2019) Adaptation and phenotypic diversification in arabidopsis through loss-of-function mutations in protein-coding genes. Plant Cell 31:1012-1025

Yang N, Liu J, Gao Q, Gui S, Chen L, Yang L et al. (2019) Genome assembly of a tropical maize inbred line provides insights into structural variation and crop improvement. Nat Genet 51:1052-1059

Ye C-Y, Tang W, Wu D, Jia L, Qiu J, Chen M et al. (2019) Genomic evidence of human selection on Vavilovian mimicry. Nat Ecol Evol 3:1474-1482

Zhang D, Zhao L, Li B, He Z, Wang GT, Liu DJ et al. (2017) SEQSpark: A Complete Analysis Tool for Large-Scale Rare Variant Association Studies Using Whole-Genome and Exome Sequence Data. Am J Hum Genet 101:115-122

Zhang F, Qu K, Chen N, Hanif Q, Jia Y, Huang Y et al. (2019) Genome-Wide SNPs and InDels characteristics of three chinese cattle breeds. Animals (Basel) 9:596

Zhang L, Jiménez-Gómez JM (2020) Functional analysis of FRIGIDA using naturally occurring variation in Arabidopsis thaliana. Plant J 103:154-165

Zhao G, Lian Q, Zhang Z, Fu Q, He Y, Ma S et al. (2019) A comprehensive genome variation map of melon identifies multiple domestication events and loci influencing agronomic traits. Nat Genet 51:1607-1615

Zhou J, Troyanskaya OG (2015) Predicting effects of noncoding variants with deep learning-based sequence model. Nat Methods 12:931-934

Zhou Y, Chebotarov D, Kudrna D, Llaca V, Lee S, Rajasekar S et al. (2020) A platinum standard pan-genome resource that represents the population structure of Asian rice. Sci Data 7:113

Zimmer EA, Martin SL, Beverley SM, Kan YW, Wilson AC (1980) Rapid duplication and loss of genes coding for the alpha chains of hemoglobin. Proc Natl Acad Sci USA 77:2158-2162

Zuk O, Schaffner SF, Samocha K, Do R, Hechter E, Kathiresan S et al. (2014) Searching for missing heritability: designing rare variant association studies. Proc Natl Acad Sci USA 111:E455-E464 